\title{
Human Welfare and Environmental Service Protection in Central Chile: The Role of Biocentrism
}

\author{
Zappi M* \\ Master Program on Environmental Management and Planning, University of Chile, Chile
}

\begin{abstract}
This study attempts to understand the valuation process for natural areas and the reasons underlying this valuation process, including the non-economic benefits that society perceives natural areas to have. A Contingent Valuation (CV) survey was used to capture citizens' Willingness to Pay (WTP) as a reflection of their perception of natural areas' benefit. In the context of the theory of planned action, socio-psychological factors were tested for influence, along with socio-demographic factors typically included as explanatory variables of WTP in the CV context. This analysis demonstrates for the first time, in Chile, that a biocentric value orientation has a direct influence on WTP for three environmental services provided by the Peñuelas Lake National Reserve, the most important of which is endangered species protection. These results shed light on the social trade-offs made in comparing multiple environmental services provided by natural areas; thus, these findings could contribute to the development of better and more rationally founded environmental education programs.
\end{abstract}

Keywords: Environmental service protection; Biocentrism; Contingent valuation; Peñuelas; Chile

\section{Introduction}

Economic valuation of natural systems has recently received increasing attention from scientists and policy-makers, mainly use conflict derived from the Environmental Goods and Services (EGS), that is, the total benefits derived from its existence (MA, 2003). On the one hand, they provide humans with a wide variety of essential material resources for living, eating, clothing, and for develop social and finally, economic activities. On the other hand, a progressive increase in social demand for recreational or "non economical" uses of these areas has been observed, that in Chile is reflected in an increase of up to $150 \%$ in the annual number of visits to areas belonging to the Protected Areas National System ${ }^{1}$ after 20 years [1]. Generally, when decisions are made concerning the fate of natural areas, money obtained from consumptive use, either direct or indirect, is the main weight factor. Non-economic benefits that are not so evidently reflected in monetary terms, are often excluded -or ignored-from the analysis that supports such decisions.

Given this context, many authors have attempted to demonstrate the Total Economic Value of natural systems ${ }^{2}$, in order to achieve the optimal allocation of natural resources [2-4]. Several techniques have been developed in the field of environmental economics to aboard this situation, being the Contingent Valuation Method (CV) one of the most popular [5]. The CV is an environmental management tool aimed at assigning monetary reference values to non-market EGS for use in the decision-making process, by building hypothetical market, where a population sample expresses their willingness to pay. Socio demographic characteristic of this sample are then used to elaborate an econometrical equation aimed to extend results to whole population, where willingness to pay (WTP) is the independent variable. However, many authors have criticized CV because of the influence of non-economic motives associated with WTP in cases where these motives have not been considered in the analysis [6-8]. It is argued,

${ }^{1}$ Chilean Protected Areas National System.

2 This concept was proposed by Barbier (1997), recognizing that natural systems provide benefits beyond their direct use and that these benefits are compounded by aggregation of the use value and the non-use value. The latter includes bequest, option and existence values. and supported by empirical evidence, that the EGS valuation process usually includes moral, spiritual and/or ethical components that reflect existence, bequest and option values. These components account for an estimated 25\% of WTP responses obtained through CV [9]. In this context, the relevance of incorporating psychological and sociological variables or factors-referred to here as Socio-Psychological Factors (SPF) that would explain WTP for moral and ethical reasons rather than the Socio-Demographic Characteristics (SDF) of the surveyed sample, is discussed. Booth [10], Kotchen and Reiling [11], Pouta [12], and Chen [13], among others, have demonstrated the need to rely on mixed economic/psychological models. Their results demonstrate that $\mathrm{CV}$ is more statistically robust when the model takes into account these measures and that a purely economic analysis undermines construct and content validity.

The main purpose of this study was to test the statistical influence of SPF and SDF on stated WTP for EGS expressed by users of a National Reserve at Central Chile, a particular area because of the multiple benefits provided to human, both consumptive and not consumptive. This study is intended to provide information to support decisions for the management of the Peñuelas Lake National Reserve. We estimate WTP as a reference currency of non-market EGS that could be incorporated into a decision-making process along with an economic benefit arising from economic activity that could potentially threaten EGS mid-range and long-range provision. Analysis of the statistical influence of the SPF on individual preferences sheds light on the attitudes that individuals have towards the natural environment. These constructs are related to their attitudes toward conservation. We

*Corresponding author: Zappi M, Master Program on Environmental Management and Planning, University of Chile, Santa Rosa 11315, La Pintana, Santiago de Chile, Chile, Tel: 56-9-97301643; E-mail: marianazappi@gmail.com

Received July 19, 2013; Accepted October 30, 2013; Published November 04 2013

Citation: Zappi M (2013) Human Welfare and Environmental Service Protection in Central Chile: The Role of Biocentrism. J Socialomics 2: 104. doi:10.4172/2167. 0358.1000104

Copyright: (c) 2013 Zappi M. This is an open-access article distributed under the terms of the Creative Commons Attribution License, which permits unrestricted use, distribution, and reproduction in any medium, provided the original author and source are credited. 
believe that this study may contribute to increasing our understanding of the value that people place on nature in Chile. Chile, like other developing countries, represents an emergent economy largely based on the extraction of natural resources; thus, it is not clear how much importance people attribute to the conservation of nature. It is even less clear whether they are willing to pay for its conservation and what the underlying factors are affecting WTP. This information is essential for the design of conservation policies and strategies that are supported by citizens and that could contribute to the development of specific environmental education plans tailored to visitor profiles, based on those visitors' knowledge level and relationship to the environment.

Finally, the results of this study are intended to contribute to strengthening both the descriptive and predictive abilities of $\mathrm{CV}$ and thus to contribute to international scientific discussion concerning the necessity of incorporating non-economic factors in the social valuation of natural areas-that is, the assignment of preferences-in the WTP analysis.

\section{Methodological Framework}

\section{Total environmental values and contingent valuation method}

Generally, when defining the fate of natural areas, money obtained from consumptive-direct or indirect-use, is usually taken as an indicator from which decisions are made. However, there are benefits perceived by society associated with 'non-market' (or 'non- commercial') EGS that so are not reflected in monetary terms, therefore often excluded from the analysis that supported those decisions. Several techniques have been developed in the field of Environmental Economics, in order to address this methodological problem. These can be based on 1) analyzing complementary or surrogate goods and services market (indirect methods), or 2) in the direct observation of individual preferences (direct or developed preferences method). Within latter, emphasizes the Contingent Valuation (CV) Method as the most employed [5]. The CV is a tool for environmental management, aimed to assigning a monetary reference to non-market EGS provided by natural systems particularly benefits associated to bequest, option, and existence value ${ }^{3}$, for it consideration in decision-making process. To this purpose, a survey is used to represent an hypothetical market, in which people is confronted with a detriment and potential loss in supply of valued EGS, due to human pressures on the systems that provide it (for details see Mitchell \& Carson, 1989). Analysis is generally based on stated willingness-to-pay (WTP) to avoid this scenario subject to an income constrain, typically explained by socio-demographic characteristics of surveyed sample. An econometric model is developed with some descriptive and predictive ability. Theoretical basis of CV has its roots in neoclassical economics, particularly in two principles that describe 'consumers' behavior: respondents know what they want according to their needs, and are able to pay more for those EGS that maximize their wellness ${ }^{4}$, making.

\section{Environmental behavior and contingent valuation method}

Environmental psychology is a relatively new discipline that focuses on relationships between individuals or social groups and their natural environment, including motives underlying human environmental behavior, to achieve behavioral solutions to environmental problems [14].

${ }^{3}$ It refers to welfare perceived by society, to know that the EGS are available for future generations, to them in the future, or that simply exist but have never made use of them, respectively.

${ }^{4}$ Principles of consumer rationality and market sovereignty, respectively.
In psychology, behavioral study can be approached using different models, each applicable under certain conditions. This study is based on the Theory of Planned Behavior (TPB) proposed by Fishbein [15] and Ajzen [16], which assumes that humans are rational beings who make systematic use of available information to make decisions and who analyze the consequences of those decisions. The TPB applies to all voluntary human behavior $[17,18]$, including consumer behavior, according to the theories of rationality and sovereignty that support $\mathrm{CV}$.

Environmental behavior can be defined as "an action performed either individually or collectively in favor of natural resources conservation, aimed at improving environmental quality" $[19,20]$. According to the TPB, behavior is immediately determined by a declared behavioral intention, which refers to a person's intention to engage in a given behavior. Intentions are assumed to capture the motivational factors that influence a behavior and are indications of how much effort people are willing to exert to engage in a behavior. As a general rule, the stronger a person's intention to engage in a behavior is, the more likely it is that the person will engage in that behavior. According to the TPB, behavioral intention is determined by mental processes with psychosocial and social foundations, collectively referred to as "sociopsychological factors" $[20,21]$ which are discussed in the next section.

Schultz et al. [22] and Kalantari et al. [23], among others, have shown that WTP stated in the context of CV is positively correlated with environmentally responsible behavior on the part of respondents, such as recycling and contributing to environmental nongovernmental organizations. In this way, WTP can be understood as a behavioral intention whose analysis and modeling thus require the incorporation of SPF as possible explanatory independent variables in the context of $\mathrm{CV}$.

\section{Socio-economical factors, socio demographical factors, and willingness to pay}

Recent research has examined the influence of SPF on WTP, and conflicting results have been obtained. Spash [24] and LópezMosquera et al. [25] investigated the relationship between WTP and the prevailing value system of a survey sample. Spash [24] found that for a sample of biology students, the acceptance of EGS quality or quantity transactions was inversely associated with the degree to which certain nature rights are perceived as inviolable, according to an 'eco-centric' value orientation. López-Mosquera et al. [25], however, reported a direct relationship between the WTP to preserve peri-urban green areas in Madrid and an 'ego-biocentric' value orientation (see section 3). Ryan and Spash [26] concluded that positive responses to WTP are responses to 'support the environmental cause' motivated by attitudes of respondents in the context of TPB, while Meyerhoff and Liebe [27] explain that much of respondents' WTP $=0$ responses are protest responses induced by the SPF that reflect a disagreement from a socio-psychological point of view rather than a real zero willingness to pay supported by economic reasons. Authors such as Bateman et al. [28] believe that people often refuse to 'play the economic game' when their position is guided by ethical or moral reasons, and consequently, a growing body of literature exists that argues that it is morally unacceptable to define environmental priorities based purely on economic criteria [29]. Urama et al. [30] demonstrated in a study conducted in Scotland that WTP to conserve the biodiversity of a river depends on a combination of socio-demographic and socio-psychological factors. Similar results were obtained in a study conducted by Chong [31] in which the combined influence of SPF 
Citation: Zappi M (2013) Human Welfare and Environmental Service Protection in Central Chile: The Role of Biocentrism. J Socialomics 2: 104. doi:10.4172/2167-0358.1000104

Page 3 of 7

and SDF on WTP for biodiversity conservation by users of a park in Malaysia was empirically demonstrated.

The results summarized above demonstrate that, as Schultz [32] postulated, SPF and its relationship to WTP are strongly linked to the social context in which the valuation study is conducted. For this reason, it is impossible to extrapolate results from other experiences. For the Chilean case, even after a thorough literature review, no studies have been found analyzing this relationship. In this sense, this paper represents a contribution to the social sciences because it could contribute to a better understanding of the nature valuation process (from the wellness perception perspective) by including citizens in the decision-making process. Finally, this study sheds light on how to improve the construct validity of $\mathrm{VC}$ and to improve its implementation at the national level.

\section{Materials and Methods}

\section{Area under study}

The Peñuelas Lake National Reserve is a located in central Chile (Fifth Region-Valparaíso), The National Reserve Lago Peñuelas is located in the Valparaiso Region, at central zone of Chile (Figure 1a,1b).

This zone characterized for its Mediterranean climate has the only Mediterranean ecosystem present in South America of the four present in the world, and present the higher level of endemism of Chile. Mittermeier et al. [33] indicate the presence of 1.800 species of endemic plants for this area, leading it to be considered as one of the world's 25 hotspots, requiring priority protection [34]. On the other hand, this is one it is an important recreation area for the local population, and it is the main source of drinking water in the Fifth Region. This three main
EGS provided by this area, are actually being threatened by an hydric scarcity, and interest conflict have been appearing, since extractive use by a private company for drinking water, endangers provision of the two others, with non monetary but a huge ethic or spiritual value.

\section{Contingent valuation method's application}

To achieve the proposed objectives, a survey was developed ${ }^{5}$ based on a review of the relevant literature and the results of a pilot study. The survey consisted of three sections, aimed at determining WTP, SPF and $\mathrm{SDF}$. The survey was conducted 'in person' by trained interviewers who surveyed a sample of 320 users of the Peñuelas Lake National Reserve during September, October and November of 2010. The following discussion briefly summarizes the contents of each of the three sections of the survey.

Section 1: WTP: The first section was designed under guidelines proposed by Arrow et al. [35] in the NOAA [36] panel report for the design of $\mathrm{CV}$ exercises in determining passive use values. People were asked whether they were willing to pay for an increase in the price of admission (dichotomous simple responses) designated as protection funds intended to ensure provision of the evaluated EGS, explicitly defined as follows, in the face of certain threats. To avoid incurring the starting price bias, we designed three versions of the survey, each with a different admission price increase level (equivalent to values of 1,2 and 3 US\$), which were applied randomly in equal proportions in the sample ${ }^{6}$. Three EGS and threats to their provision, as presented to the respondent visitors, are described below.

EGS evaluated and threats to their provision: Peñuelas Lake National Reserve belongs to the National System of Protected Areas and contains eighty-five sub-basins that flow into a main river that was

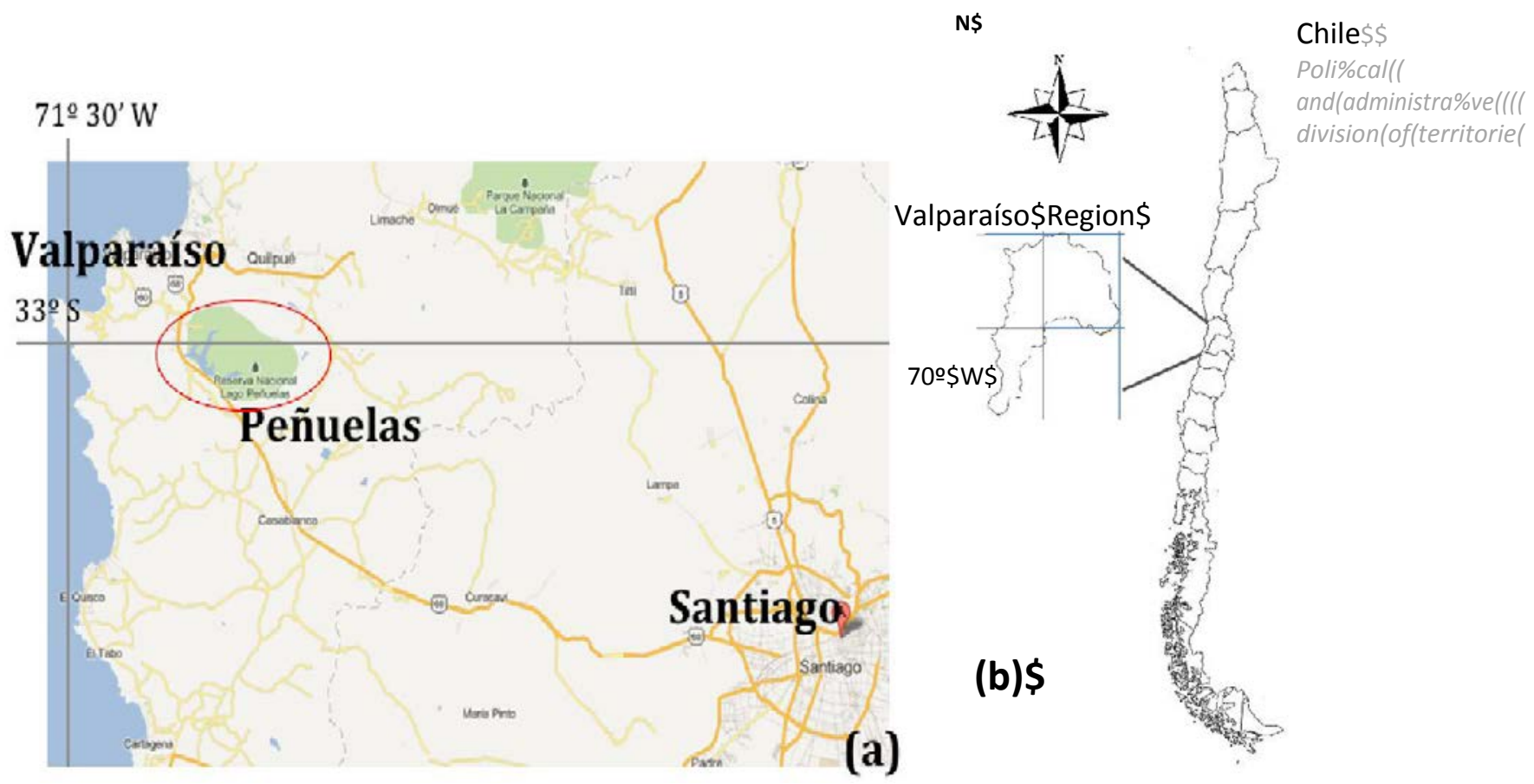

Figure 1 (a) and 1 (b): Localization of Peñuelas National Reserve, at Regional and National Level.

\footnotetext{
${ }^{5}$ An English translation of the questionnaire is available from the authors upon request.

${ }^{6}$ ANOVA analysis was performed to ensure that the initial price had no statistically significant influence on WTP.
} 
dammed in the 1970s, generating an artificial lake. This natural area provides a number of benefits to society derived from direct use, which must be reconciled with the ecosystem functions that are essential for the species that inhabit the area and that are now under threat. This zone, characterized by its Mediterranean climate, has the only Mediterranean ecosystem in South America of the four that exist in the world, and it has the highest level of endemism in Chile.

Drinking water: The main reasons for damming the river were to store drinking water during the winter and provide drinking water to the cities of Viña del Mar and Valparaíso during the summer. A private company currently manages this service.

Endangered species protection: The reserve provides suitable habitat for the development of several species of flora and fauna, many of them endemic and with some level of conservation concern. The lake is the only area with a significant concentration of birds in the Metropolitan and Valparaiso Regions of Chile. It is also a priority site for conservation. Mittermeier et al. [33] indicate the presence of 1.800 species of endemic plants in this area, leading it to be considered one of the world's 25 hotspots requiring priority protection [34].

Scenic beauty: The lake and the wildlife that inhabit its environment constitute a beautiful landscape. Every year, hundreds of people arrive at this place to enjoy the beauty of the landscape and to see the animals and plants that live here. In addition, it is very close to three of the most populated cities in Chile: Valparaíso $(30 \mathrm{~km})$, Viña del Mar $(45 \mathrm{~km})$, and Santiago $(94 \mathrm{~km})$.

Threats against their provision: Currently, urbanization and mining threaten to alter the quality and quantity of the river basin and Peñuelas Lake, which would alter the habitat of protected animals and plants and degrade the natural beauty of the area. If this happens, visitors would no longer be able to enjoy the current landscape, the conservation of protected native species would be threatened, and the ability to provide drinking water to Viña del Mar and Valparaíso could be diminished. Respondents who answered negatively to the question concerning willingness to pay were asked for their reasons for answering negatively, and respondents who answered affirmatively were asked to indicate, on a scale from 1 to 5 , how sure they were that they would pay the accepted increase. This was taken as a criterion to rule out biased responses?

Each respondent was asked to indicate what percentage of the funds that would be generated by the admission price increase he or she would assign to each of the three valued EGS, and each respondent was asked if they had children (to test the 'parental effect ${ }^{8}$ ). The respondents were also asked to indicate, on a scale from 1 to 3 , the relative importance of each of the four following reasons for conserving

\footnotetext{
7 This practice primarily aimed to rule out complacency bias, in which the respondent answers 'yes' to a willingness-to-pay question out of belief that the interviewer expects or will benefit from a positive response and will disapprove of a negative response.

${ }^{8}$ This variable is not related to TPB, but many authors suggest that it is a factor considered by the individual when mental processes related to the environmentalhuman relationship are evoked.

9 According to TPA, behavioral intention is induced directly by social and personal SPF, called 'attitude' and 'subjective norms', which are represented by environmental concern and conditional cooperation, respectively. A value system exerts a direct influence on behavioral intention and also influences behavioral intention indirectly through its influence on attitude and subjective norms [16].

10 The original scale only captures biocentric and anthropocentric orientation. Amérigo's adaptation showed that biocentric value orientation should be divided into biocentric and ego-biocentric, as these results yield more robust statistical results.

${ }^{11}$ An English translation of the questionnaire is available from the authors upon request.
}

attributes of the reserve. These relative importance ratings were not intended to define possible independent variables but rather to aid in understanding how information is processed and how people assign a total economic value to the area.

- Because I enjoy knowing they are available to me in the future. (Option value)

- Because I enjoy knowing that others enjoy them now. (Altruistic value)

- Because it is important that it be available for future generations. (Bequest value)

- Because I enjoy knowing that they exist, even if nobody ever uses them. (Existence value)

Section 2: SDF: Respondents were asked about their age, gender, departure city, current occupation, family size, and education and income levels; income levels were requested to avoid negative or false answers. The purpose of the departure city question was to identify whether being a direct beneficiary of drinkable water influenced the valuation process (assuming that all respondents come from the place where they live). Along the same lines, an additional question was asked about number of annual visits to the reserve.

Section 3: SPF: Three SPF belonging to TPB were tested for their influence on the EGS valuation process by analyzing their influence on WTP: environmental concern, value system, and conditional cooperation $^{9}$. Because SPF are mental processes that induce behavior, a specific tool called a 'psychometric scale' was used for its operationalization. A psychometric scale uses a set of statements, each pertaining to one item, about which respondents must express the extent of their agreement or disagreement on a 1-5 scale $(1=$ no agreement, $5=$ very strong agreement) [37]. The basic assumption is that the response evoked by each item is a function of the position of the item in the continuum of measured SPF; that is, stronger agreement indicates that the respondent places greater value on the item. The final score for each item is obtained by adding or averaging the respondents' ratings for that item. For each SPF, we used a scale that was developed by experts in the field and that has been used frequently and validated in the literature. Environmental concern was operationalized using the new environmental paradigm scale designed by $[6,7,11,20,38,39]$. To measure people's value systems, we used the Tompson and Barton [40] scale, adapted to Spanish by Amérigo [41]. This scale consists of 15 items and measures 3 value orientations-anthropocentric, biocentric and ego-biocentric ${ }^{10}$ - to distinguish people who believe that nature must be protected because it is important for human development due to its intrinsic value independent of humans or because of wellness perceived to be derived from contact with nature and from its protection. Conditional cooperation has been described as one of the main social factors influencing behavioral intentions in the context of the TPA $[42,43,44]$. A scale adapted from Frey and Meier was used in this study.

The reliability of the scales was assessed using Cronbach's alpha and exploratory factor analysis [45]. Both of these tools are based on analysis of the covariance of the responses obtained in the pilot study, and they make it possible to determine the extent to which all items contribute to defining the central construct being measured and to eliminate those items that may interfere. All of the scales used were judged to be reliable according to these established criteria ${ }^{11}$.

Data analysis: Modeling of WTP: Survey results were econometrically modeled through binary logistic regression calibrated 
using the statistical program SPSS $19.0^{12}$. This method quantifies how certain independent variables that are presumed to be relevant (SPF and SDF) influence the probability of occurrence ${ }^{13}$ of a dichotomous event (i.e., a respondent being willing or not willing to pay the proposed admission price increase). According to Mitchel and Carson [46] and Loomies et al. [47], this is the statistically correct way to model dichotomous choice responses in CV. After different combinations of SPF and SDF were modeled as independent (explanatory) variables of $\mathrm{P}(\mathrm{WTP}=1)$, a final regression model was selected on the basis of its global statistical significance and the statistical significance of each variable in the model $(\mathrm{p}<0,05)^{14}$.

\section{Results}

\section{General background}

Of the 320 people surveyed, $24.1 \%(n=77)$ responded negatively to the question about willingness to pay, with no significant differences being detected among the three proposed amounts. There were no incomplete questionnaires or protest responses. The reasons for responding negatively to the question on WTP were the following:

- Economic reasons: price too high to come as a family; there are other costs associated with travel (petrol, tolls, etc.); there are cheaper places to visit for the weekend. $(55 \%, \mathrm{n}=42)$

- Services provided are not worth the proposed increase: basic services provided (toilets, tables, etc.) do not justify the increase; the lake is dry in some seasons. $(45 \%, \mathrm{n}=35)$.

The lack of negative responses justified on moral or ethical grounds is noteworthy. The main reason for affirmative answers concerning willingness to pay pertained to the legacy value of the ESG, followed by altruistic, non-use and option values. The protection of threatened species accounted for $41 \%$ of the affirmative responses, followed by the landscape (31\%) and finally the provision of drinking water (28\%).

\section{Econometric modeling of WTP}

As it was mentioned, an econometric model was constructed, with WTP as a dependent variable, and SPF and SDF as independent variables. Table 1 presents the variables that were included in the model that explains $\mathrm{P}(\mathrm{WTP}=1)$ (that is, to be willing to pay) with their corresponding regression coefficients, or explanatory variables $\beta$; the magnitudes of $\beta$ reflect the intensity of the relationship among willingness to pay and the reason under study, and the sign of $\beta$ reflects the direction of the effect: direct (positive) or inverse (negative).

\begin{tabular}{|c|c|c|}
\hline Variable & $\boldsymbol{\beta}$ & Standard Error \\
\hline Gender (women) & $-0,754$ & $0,363^{*}$ \\
\hline Income level & 0,099 & $0,041^{*}$ \\
\hline Proposed admission increase level & $-0,010$ & $0,000^{*}$ \\
\hline Biocentric value orientation & 0,602 & $0,286^{*}$ \\
\hline Constant & $-1,09$ & 1,528 \\
\hline
\end{tabular}

${ }^{*} \mathrm{P}<0,05$. Model statistical summary: -2 Like Likelihood: 335,712; Cox and Snell's square R: 0,053

Table 1: Significant Explanatory (independent) Variables of the WTP Statistic Model.

${ }^{12}$ Developed and provided by IBM. Since not temporary license were available, IBM Chile had the kindness to lend a temporary license, for the only purpose of performing this study.

${ }^{13}$ From this point on, the probability of a 'yes' response to the WTP question is denoted by ' $\mathrm{P}(\mathrm{WTP}=1)$ '

${ }^{14}$ It is worth mentioning that the 'variables' used to model WTP were the mean values of the total sample.
A P $(\mathrm{WTP}=1)$ was obtained by introducing into this equation average values from the survey results for each variable. The probability of a response 'yes' response to a proposed increase in the price of admission for the surveyed sample was 0,79 . Through mathematical transformation, the mean WTP was determined from this probability. The mean WTP of the surveyed sample to protect the EGS evaluated was $\$ 2,412$ (Chilean pesos, equivalent to 5 US\$).

\section{Analysis of results}

Willingness to pay depended on a combination of SPF and SDF. The absence of models for $\mathrm{P}(\mathrm{WTP}=1)$ was explained purely by SDF in the set of statistically significant models (Appendix 2) should be noted. It should also be noted that, among the variables included in the selected model, biocentric value orientation had better explanatory and predictive power $(\beta)$ than income level. This result agrees with results obtained by Booth [10] in a CV study that analyzed motives behind WTP for watershed protection in the state of Wisconsin, USA, and results obtained by Urama et al. [30] and Spash et al. [48] in successive studies that analyzed the reasons behind WTP for restoring a lake ecosystem in Scotland. Both of these cases emerged within a TPB context, where SPF seemed to be better explanatory variables of WTP than SDF. With respect to the relative influence of each of the explanatory variables, we first noted that gender (women) was inversely correlated to WTP, which means that women were less willing to pay for conservation than men. Inverse relationships between income level and proposed increase amount to WTP was expected, according to the econometric basis of $\mathrm{CV}$, reflecting a balancing with other needs by the respondents. However, the relative influences of these two factors on WTP are less than those of gender and biocentric value orientation, as shown by the regression equation for WTP. For biocentric value orientation, no direct or inverse relationship to WTP was expected. An indirect influence could point to an ethical and moral inability to transact nature and its components.

\section{Value orientation and total economic values compounds}

Three EGS provided by Peñuelas were evaluated, and people were asked to indicate what percentage of the funds obtained from an increase in the admission price they would assign to each EGS evaluated. Species protection received the greatest proportion (41\%), followed by scenic beauty (31\%) and then by provision of drinking water to Viña del Mar and Valparaíso (28\%). These findings are consistent with the results reported above concerning a biocentric value orientation playing an important role in determining individual preferences because it is included among the variables that explain WTP. In addition, this result could be explained by the sample asymmetry with respect to departure city because altruistic value was the reason rated least important among the reasons to conserve the EGS evaluated (see below). Last, with respect to TEV underlying WTP, the most important values was the legacy value, followed by the bequest value, the existence value, and the altruistic value. This finding confirms the importance of non-use values among the TEV of natural areas, in comparison with use values, which are often the only values considered in the decision-making process.

\section{Discussion}

Based on a CV survey of visitors to RNLP, it can be confirmed for the first time in Chile that certain psycho-social elements, the influences of which have not been previously analyzed, are involved in the process of evaluating EGS. Calculated WTP has a positive and statistically significant value, which, according to the theoretical basis of the CV method, means that the EGS evaluated has a direct influence on users' welfare. Moreover, a contribution is made to understanding the 
valuation process. Based on the relative importance assigned to them, 'non-market' EGS and particularly 'endangered species protection' were found to be the most important and thus to contribute most to the welfare of respondents. According to Bräuer, this information '... helps political authorities to transform environmental problems into policy'. However, it should be noted that certain limits are imposed by the CV method, especially with respect to extrapolating conclusions. The results were obtained from a biased sample of users of a natural reserve. This factor suggests that further research on the influence of SFP on WTP in other CV contexts should be conducted, including evaluating other EGS because human preferences are influenced by previous experiences and by the immediate context.

With respect to the relative influence of each of the explanatory variables, we first noted that gender (women) was inversely correlated to WTP, which means that women were less willing to pay for conservation than men. Conflicting results have been obtained in other studies with respect to this variable. While reported that Zewdu and Yemesrach [5] found no statistical influence of this factor on WTP, whereas Adebo and Ajewole [49] reported a higher proportion of 'yes' responses to WTP from women than from men. The results obtained in the present study may be explained by the fact that most of the women surveyed identified themselves to be housewives or unemployed (data not shown) and thus may have a low income level, a factor that is also inversely correlated to WTP, as Table 1 shows. In addition, as indicated by Spash [48], the sample was predominantly male, and this asymmetry may have influenced the pattern of results.

Inverse relationships between income level and proposed increase amount to WTP was expected, according to the econometric basis of $\mathrm{CV}$, reflecting a balancing with other needs by the respondents. These variables also exhibited statistically significant influences on WTP in studies performed by Cerda [3], Spash [7], Bhandari and Heshmati [50] and Szabó [51], among others. However, the relative influences of these two factors on WTP are less than those of gender and biocentric value orientation, as shown by the regression equation for WTP.

For biocentric value orientation, no direct or inverse relationship to WTP was expected. An indirect influence could point to an ethical and moral inability to transact nature and its components [48]. Inglis [52] reported that a disposition to contribute to a biodiversity protection fund in a natural park in Australia depended on a biocentric value orientation. On the other hand, Booth [10] found no direct influence of this factor on WTP but found an indirect influence through other TPB components, including attitudes and subjective norms ${ }^{7}$. These results contrast with those obtained in the present study, in which attitude and conditional cooperation were not shown to have a statistically significant influence on WTP.

As for variables that were not included in the final model of WTP, a direct influence of the number of annual visits to Peñuelas was expected. However, it was observed that when the number of annual visits increased, the proportion $\mathrm{WTP}=0 / \mathrm{WTP}=1$ increased as well. No statistically significant relation was found, but the tendency is marked and could reflect economic reasons. On the other hand, the departure city was expected to enter into the equation; people traveling from Viña del Mar and Valparaíso were expected to be more willing to pay because they perceived the extra benefit of fresh water provided to their cities from the lake, unlike other visitors. As with gender, asymmetry of the sample with respect to this item (90\% of the visitors were from Santiago vs. $10 \%$ from Viña del Mar) could explain this finding. Education level frequently exerts a direct influence on WTP $[12,7,30,50,53]$ because it is usually highly correlated to income level; however, a previous study performed at Peñuelas by Cerda [3] detected no statistically significant influence of this variable on WTP.

Finally, with respect to age and the parental effect, Torgler et al. [54] reported an inverse relation between age and WTP but no statistically significant parental effect, while the opposite was reported by Duppont [55]: a statistically significant parental effect but no statistically significant effect of gender. In the present work, the lack of influence of parental effect could be explained by the fact that 'bequest value' was indicated to be the most important reason to protect EGS provided by Peñuelas, independent of whether the respondent was a parent.

The results of this study could contribute to environmental management decision-making processes and to implementation of conservation actions that would be supported by citizens. It is clear that an admission price increase or proposed voluntary contribution designated for conservation would have a high probability of acceptance. This is not a minor finding in the Chilean context, where, as in many Latin American countries, public funds designated for conservation are limited. Granting people the option to allocate some economic resources to natural system conservation, instead of spending them on the consumption and waste typical of capitalism, might also be a contribution to market democracy and to national and world sustainability. On the other hand, the social cost related to prioritizing water supplies for urban purposes-which currently represents the primary threat to the RNLP-could be incorporated to estimate compensation measures demanded of the private company that manages this activity in the case of noncompliance; in the best-case scenario, such costs could lead to limits on the maximum extraction levels of fresh water.

\section{References}

\section{1. (Corporación Nacional Forestal) CONAF (2011).}

2. Barbier E, Acreman M, Knowler D (1997) Economic Valuation of Wetlands Guide for Polici makers and planners. Ramsar Convention Bureau Gland Switzerland

3. Cerda C (2003) Economic valuation on natural heritage of Peñuelas Lake National Reserve. Dissertation for Environmental Management Magister Universidad de Chile.

4. Cerda C, De La Maza C, Rodríguez M (2010) Valoración económica de servicios ambientales: ¿Tiene algo que decir la sociedad? Revista Parques.

5. Zewdu B, Yemesrach A (2003) Willingness-to-pay for protecting endangered environments: the case of Nechsar National Park. Addis Ababa, Ethiopia: Organisation for Social Science Research in Eastern and Southern Africa.

6. Cooper P, Poe G, Bateman I (2004) The structure of motivation for contingen values: a case study of lake water quality improvement. Ecological Economics 50: 69-82.

7. Spash C (2006) Non-Economic motivations for contingent values: rights and attitudinal beliefs in the willingness to pay for environmental improvements. Land Economics 82: 602-622.

8. Martín-López B, Montes C, Benayas J (2007) The non-economic motives behind the willingness to pay for biodiversity conservation. Biological Conservation 139: 67-82.

9. Spash C, Stahl S, Getzner M (2005) Exploring alternatives for environmental valuation. In Alternatives for Environmental Valuation Getzner, Spash \& Stagl (eds.) London: Routledge.

10. Booth D (2000) Biocentric Environmental Values and Support for the Ecological Restoration of Urban Watersheds. Technical Report \#8. from the USEPA NSF/USDA STAR Watershed Program. Department of Economics, Institute for Urban Environmental Risk Management Marquette University, Milwaukee, Wisconsing, USA.

11. Kotchen M, Reiling S (2000) Environmental attitudes, motivations, and contingent valuation of nonuse values: a case study involving endangered species. Ecol Econ 32: 93-107. 
Citation: Zappi M (2013) Human Welfare and Environmental Service Protection in Central Chile: The Role of Biocentrism. J Socialomics 2: 104. doi:10.4172/2167-0358.1000104

Page 7 of 7

12. Pouta $E$ (2003) Attitude-behaviors Framework in contingente valuation of forest conservation. Doctoral dissertation at the Department of Forest Economics, University of Helsinki.

13. Chen J (2007) Environmental Attitudes and Willingness to Pay More for Environmental Protection-Results from the 2000 General Social Survey. American Sociological Association: Annual meeting. New York, USA.

14. Pol E, Valera S, Vidal T (1999) Psicología Ambiental y Procesos Psicosociales in Psicología Social, pp 317-334. Madrid: McGraw-Hill

15. Fishbein M, Ajzen I (1975) Belief, attitude, intention and behavior: an introduction to theory and research. Reading Massachusetts: Addison-Wesley.

16. Ajzen I (1991) The theory of planned behavior. Organizational Behavior and Human Decision Processes 50: 179-211.

17. Randall M, Wolff J (1994) The time interval in the intention-behavior relationship: Meta-analysis. Brit J Soc Psych 33: 405-418.

18. Sheppard B, Hartwick J, Warshaw R (1988) The theory of reasoned action: A meta-analysis of past research with recommendations for modifications and future research. J Consum Res 15: 325-343.

19. Castro R (2006) Persona, sociedad y medio ambiente : perspectivas de la investigación social de la sostenibilidad. Dirección general de Educación Ambiental y Sostenibilidad. Consejería de Medio Ambiente, Junta de Andalucía.

20. Aguilar-Luzón C, García-Martínez J, Monteoliva-Sánchez A, Salinas Martínez De Lecea J (2006) El modelo del valor, las normas y las creencias hacia el medio ambiente en la predicción de la conducta ecológica. Medio Ambiente y Comportamiento Humano $7:$ 21-44.

21. Estrada Roca G (2006) Análisis de las actitudes y conocimientos estadísticos elementales en la formación del profesorado. Doctoral dissertation at Didactic of mathematics department and experimental sciences. Universidad Autónoma de Barcelona.

22. Schultz P, Gouveia V, Cameron L, Tankha G, Schmuck P, et al. (2005) Values and their relationship to environmental concern and conservation behavior. $J$ Cross-Cult Psychol 36: 457-475.

23. Kalantari K, Fami H, Asadi A, Mohammadi A (2007) Investigating Factors Affecting Environmental Behavior of Urban Residents: A Case Study in Tehran City- Iran. American Journal of Environmental Sciences 3: 67-74.

24. Spash C (1997) Ethics and Environmental Attitudes With Implications for Economic Valuation. J Environ Manage 50: 403-416.

25. López-Mosquera N, Barrena R, Sánchez M (2010) Influencia de los valores personales en la valoración económica de los visitantes de espacios verdes periurbanos. Una aplicación de la Teoría Means-End Chain. Tourism Management.

26. Ryan A, Spash C (2010) Measuring Beliefs Supportive of Environmental Action and Inaction: A Reinterpretation of the Awareness of Consequences Scale. Socio- Economics and the Environment in Discussion.

27. Meyerhoff J, Liebe U (2004) Protest Beliefs in Contingent Valuation: Explaining Their Motivation. $8^{\text {th }}$ Biennial Scientific Conference International Society for Ecological Economics.

28. Bateman IJ, Carson B, Day M, Hanemann N, Hanley T, et al. (2002) Economic Valuation with Stated Preference Techniques - A Manual. Edward Elgar Publishing Ltd.

29. Spash C (1993) Economics, ethics and long-term environmental damages. Environ Ethics 15: 117-132.

30. Urama C, Kenyon W, Burton R, Potts J (2006) Integrated Value Mapping for Sustainable River Basin Management: Economics, Ethics and Social Psychology. African Technology Policy Studies Network.

31. Chong $P$ (2005) Environmental attitudes and willigness to pay for highlands conservation: the case of Fraser's Hill, Malaysia. Masters thesis, Universiti Putra Malaysia.

32. Schultz P (2002) Environmental Attitudes and Behaviors Across Cultures. Online readings in psychology and culture. International Association for CrossCultural Psychology.

33. Mittermeier RA, Myers N, Thomsen JB, Da Fonseca GA, Olivieri S (1998) Biodiversity hotspots and major tropical wilderness area: approaches to setting conservation priorities. Conservation Biology 12:516-520.
34. Myers N, Mittermeier R, Mittermeier C, da Fonseca G, Ken J (2000) Biodiversity hotspots for conservation priorities. Nature 403: 853-858

35. Arrow K, Solow R, Portney P, Leamer E, Radner R, et al. (1993) Report of the NOAA Panel on Contingent Valuation. National and Oseanic Atmosferic Administration. United State Department of Commerce.

36. NOAA (2011) Environmental Valuation: Principles, Techniques, and Applications.

37. Ávila Baray HL (2006) Introducción a la metodología de la investigación. Biblioteca Virtual de Economía, Derecho y Ciencias Sociales, Universidad de Málaga.

38. Van Liere K, Dunlap RE (1978) The New Environmental Paradigm. Journal of Environmental Education 9: 10-19.

39. Berenguer J, Corraliza J (2000) Environmental Concern and Ecologica Behavior. Psycothema 12: 325-329.

40. Thompson SCG, Barton M (1994) Ecocentric and anthropocentric attitudes toward the environment. J Environ Psych 14: 149-157.

41. Amérigo $M$ (2009) Concepciones del ser humano y la naturaleza desde e antropocentrismo y el biocentrismo. Medio Ambiente y Comportamiento Humano 10: 217-234.

42. Frey B, Meier S (2006) Social Comparisons and Pro-social Behavior: Testing 'Conditional Cooperation' in a Field Experiment'. American Economic Association 94: 1717-1722

43. Gächter S (2006) Conditional cooperation: Behavioral regularities from the lab and the field and their policy implications. CeDEx Discussion Paper No. 200603. Centre for Decision Research and Experimental Economics The University of Nottingham

44. Meyerhoff J, Lienhoop N, Elsasser P (2007) Stated preferenes methods for environmental valuation: applications from Austria and Germany. MetropolisMerlag, Germany.

45. Castanedo Cecadas C (1995) Escala para la evaluación de las actitudes pro-ambientales (EAPA) de alumnos universitarios. Revista Complutense de Educación 6: 253-278.

46. Mitchel R, Carson T (1989) Using Surveys to Value Public Goods. The contingente Valuation Method. Resources for the Future, Washington DC

47. Loomis J, Bell P, Coonie H, Asmus C (2009) A Comparison of Actual and Hypothetical Willingness to Pay of Parents and Non-Parents for Protecting Infant Health: The Case of Nitrates in Drinking Water. Journal of agricultural and applied economics 41: 697-712.

48. Spash C, Urama K, Burton R, Kenyon W, Shannon P, et al. (2009) Motives behind willingness to pay for improving biodiversity in a water ecosystem: Economics, ethics and social psychology. Ecol Econ 68: 955-964.

49. Adebo GM, Ajewole O (2012) Gender and the Urban Environment: Analysis of Willingness to pay for Waste Management Disposal in Ekiti-State, Nigeria American International Journal of Contemporary Research 2: 228-236.

50. Bhandari A, Heshmati A (2009) Willingness to Pay for Biodiversity Conservation Technology Management, Economics and Policy Papers. Discussion Paper No. 2009:38. Technology Management, Economics and Policy Program. Seou National University. College of Engineering.

51. Szabó Z (2010) Increasing the validity of valuing biodiversity: reducing protest responses by deliberative monetary valuation. Corvinus University of Budapest Environmental Economics Department, Budapest, Hungary.

52. Inglis J (2008) Using human-environment theory to investigate human valuing in protected areamanagement. Doctoral dissertation at University of Victoria, Autralia.

53. Valdivia Alcalá R, Cuevas Alvarado M, Sandoval Villa M, Lozano J (2009) Estimación econométrica de la disponibilidad a agar por los consumidores de servicios recreativos turísticos. Terra Latinoamericana 27: 227-235.

54. Torgler B, Frey B, Wilson C (2007) Environmental and Pro-Social Norms: Evidence from 30 Countries. The Fondazione Eni Enrico Mattei Note di Lavoro Series Index.

55. Dupont D (2004) Do children matter? An examination of genderdifferences in environmental valuation. Ecological Economics 49: 273-286. 